\title{
A review of bone mineral density scans referred by a community- based menopause clinic in 1997
}

\author{
Alan Miles, BSc, 5th Year Medical Student \\ The University of Edinburgh, Edinburgh, UK.
}

\begin{abstract}
Kate Weaver, MB ChB, BSc, Clinical Research Fellow; Anna Glasier, MD, FRCOG, MFFP, Consultant Gynaecologist and Director
\end{abstract}

Dean Terrace Family Planning and Well Woman Clinic, Edinburgh, UK.

Correspondence: Dr Kate Weaver, Clinical Research Fellow, The Dean Terrace Centre, 18 Dean Terrace, Edinburgh, EH4 1NL, UK. Tel: $01313327941 / 3436243$ Fax: 01313322931

(Accepted March $\left.28^{\text {th }}, 2000\right)$

\begin{abstract}
Summary
Osteoporosis is a growing public health issue for the UK's ageing population. Many older women want know if they are at risk of osteoporosis and if preventive treatment, particularly in the form of hormone replacement therapy (HRT), would be advisable. This results in many women being referred for bone mineral density (BMD) scanning, whether or not they have recognised risk factors for osteoporosis.

We present the results of a review of 228 referrals for BMD scan from a community-based menopause clinic. The results are categorised by the indications for the scan. The implications for the future of BMD investigations are considered in the light of ongoing discussion about population screening.
\end{abstract}

\section{Key words}

bone mineral density scan, hormone replacement therapy, menopause, osteoporosis

\section{Key message points}

- Population screening for osteoporosis in menopausal women is not currently recommended in the UK.

- Department of Health guidelines identify women at higher risk of osteoporosis, who may benefit from screening with bone mineral density (BMD) scans.

- Many women without known risk factors for osteoporosis request BMD scans in the perimenopause.

- Our review suggests such motivated women may often benefit from a BMD scan in helping to weigh up their individual risks and benefits from hormone replacement therapy.

\section{Introduction}

Osteoporosis is associated with considerable morbidity and mortality. With an ever-increasing proportion of the UK population falling into the elderly age group, osteoporotic fractures impose a growing financial burden on the NHS and social services. ${ }^{1}$

The general public is becoming more knowledgeable about osteoporosis, and menopausal women in particular are now inclined to think about osteoporosis and to weigh up the risks and benefits of HRT.

It is widely agreed that population screening for osteoporosis cannot be recommended in the UK at this time. ${ }^{2}$ Nevertheless, menopause clinics see many healthy women, without apparent risk factors, referred by a GP or self-referring for osteoporosis screening.

BMD measurement by Dual Energy X-ray Absorptiometry (DEXA) scanning provides a good assessment of fracture risk. ${ }^{3}$ However, it is less good at identifying the individuals who will go on to have fractures and for whom preventive therapy may be indicated. In the setting of a menopause clinic, preventive therapy is most likely to take the form of HRT.

We undertook a review in an attempt to determine the pattern of referrals for DEXA scanning from a community menopause clinic. The results of scans from 228 women referred in the calendar year 1997 were examined and classified by risk group.

\section{Method}

Patients were seen at a large family planning and well woman clinic with a well established menopause service ${ }^{4}$ and had DEXA scans at the medical physics department of the local teaching hospital. Before referral, the women were all seen by a doctor for discussion of their individual risks of osteoporosis and the risks and benefits of HRT. All were willing to seriously consider the use of HRT or bisphosphonates if indicated.

The scan results were divided into five categories (defined below), according to the indication for the scan. Categories 1-3 follow the national guidelines for DEXA scanning issued in 1998 by the Department of Health. ${ }^{5}$ Categories 4 and 5 include women without known risk factors for osteoporosis, but reflect the characteristics of women attending the menopause clinic. The DEXA scans were reported according to the WHO guidelines in which osteopenia is defined as a BMD between 1 and 2.5 standard deviations below the mean for the young normal population and osteoporosis as a BMD more than 2.5 standard deviations below the mean for the young normal population.

The categories of scan referral were defined as below:

1. Women with a high clinical index of suspicion for established osteoporosis, including those with a history of low impact fracture, radiographic evidence of osteoporosis, corticosteroid therapy, height loss or back pain suggestive of vertebral collapse. A total of 47 women fell within this category, representing $21 \%$ of the population reviewed.

2. Women with presumed oestrogen deficiency pre-dating the average age of the menopause, including women with premature natural or iatrogenic menopause before the age of 45 and those with prolonged secondary amenorrhoea or primary hypogonadism. Twenty-seven women, $12 \%$ of the total reviewed, fell into this category.

3. Women with increased risk of osteoporosis at or after the age of the menopause because of factors such as family history of osteoporosis, smoking, body weight below $58 \mathrm{~kg}$, thyroid disease or rheumatoid arthritis. In this category there were 85 women, representing $37 \%$ of the total. 
4. Women already using HRT but with no identifiable risk factors for osteoporosis. DEXA scans were used to help these women weigh the risks of continuing HRT (e.g. side effects, increased breast cancer risk) against its bone-protective effects. This category included 39 women, $17 \%$ of the total in the review.

5. Women with no identifiable risk factors for osteoporosis and not currently taking HRT, but concerned about osteoporosis and considering using HRT. There were 30 women in this group, representing $13 \%$ of the total.

\section{Results}

Table 1 shows the scan results for the women by category, as well as numbers of women advised to use preventive therapy after discussion of the result. As expected, women in category 1 had the highest incidence of abnormal scans, with $43 \%$ classed as osteoporotic. In categories 2 and 3, $19 \%$ and $21 \%$ respectively were osteoporotic and in both of these categories 59\% were osteopenic. Most of the women without known risk factors in categories 4 and 5 had normal DEXA scans. However, $10 \%$ of women in each of these categories had osteoporosis.

The table also shows the percentage of women advised to start preventive treatment. Of all the women with scans consistent with osteoporosis, only one was not advised to immediately start preventive treatment. She was a 43-yearold woman who consulted with menopausal symptoms, but was still regularly menstruating. She was advised to commence HRT after the menopause. A variable number of those with osteopenia were advised to commence preventive treatment, depending largely on the presence or absence of recognised risk factors for osteoporosis.

\section{Treatment compliance}

The patients who were advised to start treatment (HRT or bisphosphonates) for low BMD were sampled to estimate compliance. A sample of 23 of these patients was chosen using random numbers from Microsoft Excel. They were contacted directly or via the GP, to find out if they had commenced treatment and if they had persisted 18-24 months later. Information was available for 18 out of the sample of 23 women; 16 had started treatment and 14 persisted with treatment (one withdrawal was due to appearance of a breast lump, the second was due to a deep vein thrombosis). This represents at least a $61 \%$ treatment compliance rate at 18-24 months.

\section{Discussion}

UK Department of Health Guidelines recommend that women who fall into categories 1, 2 and 3 undergo screening for osteoporosis. Indeed in these groups we detected a high rate of both osteoporosis and osteopenia.
While population screening is not recommended in this country, the women in categories 4 and 5, without known risk factors for osteoporosis, represent the types of women that are increasingly asking their GPs for bone scans. Women in these two categories account for $30 \%$ of our referrals. Rates of osteoporosis and osteopenia in categories 4 and 5 were lower than in categories 1 to 3 , but were nevertheless significant; $10 \%$ had osteoporosis and $40 \%$ had osteopenia.

A BMD scan costs around $£ 38$ in Lothian. It is important to ask if scanning women in categories 4 and 5 is an appropriate use of resources. Most of these women were using the scan result to decide whether to take, or continue taking, HRT. One undisputed benefit of long-term HRT is osteoporosis prevention, ${ }^{6}$ so this does represent a reasonable use of the BMD scan results. In addition, the sample of compliance suggests that this is a good use of resources since a good proportion of women did act on the advice given as a result of the BMD scan, and did continue to use treatment up to 2 years later. Our compliance rate of $61 \%$ at 18 to 24 months sounds relatively low, but compares favourably with other studies. Experts acknowledge that long-term compliance with HRT is a common problem, up to $75 \%$ of women stopping HRT within the first 6 months. Even among women with risk factors for osteoporosis, the 1 -year compliance rate was only $50 \%$ in one study. 7

Some of the women we reviewed never commenced the treatment advised for them. However, they all received lifestyle advice about diet and exercise, and many continued under specialist follow-up, so it can still be argued that they may benefit from knowing they have low BMD. It may be that these women had more complex medical histories, with more potential risks to taking HRT. Our survey did not collect data to answer this question.

\section{Conclusion}

We suggest that the BMD scan is a useful tool, which enhances the value of the advice we can give to individual women on long-term HRT use. It must be acknowledged that the advice we can give on the basis of BMD scan results is still incomplete; although HRT undoubtedly delays loss of bone mineral density, there remain questions about the optimal duration and timing of HRT use to prevent osteoporotic fractures whilst minimising its unwanted effects. Currently, most women who use HRT take it for just a few years in the perimenopause. However there are also arguments for a finite period of use later in life, when the risks of fracture are higher, or for indefinite use, or for alternating 5 years of use with 5 years off HRT.

It is hard to deny a woman a scan if she requests it. Perhaps a pragmatic guideline would be to offer a BMD scan to women with relative contraindications to HRT who are nevertheless considering the benefits of using HRT, and

Table 1 Summary: BMD scan results by category of referral and numbers (\%) of women advised to commence preventive treatment in each group. See text for explanation of the categories of referral.

\begin{tabular}{|c|c|c|c|c|c|c|}
\hline $\begin{array}{l}\text { Category } \\
\text { (number of } \\
\text { women in category) }\end{array}$ & $\begin{array}{l}\text { Number of } \\
\text { women with } \\
\text { normal BMD (\%) }\end{array}$ & $\begin{array}{l}\text { Number of } \\
\text { women with } \\
\text { normal scan } \\
\text { advised to start } \\
\text { treatment }(\%)\end{array}$ & $\begin{array}{l}\text { Number of } \\
\text { women with } \\
\text { osteopenic scans } \\
(\%)\end{array}$ & $\begin{array}{l}\text { Number of } \\
\text { women with } \\
\text { osteopenic scans } \\
\text { advised to start } \\
\text { treatment }(\%)\end{array}$ & $\begin{array}{l}\text { Number of } \\
\text { women with } \\
\text { osteoporotic scans } \\
(\%)\end{array}$ & $\begin{array}{l}\text { Number of } \\
\text { women with } \\
\text { osteoporotic scans } \\
\text { advised to start } \\
\text { treatment }(\%)\end{array}$ \\
\hline One (47) & $9(19)$ & $2(22)$ & $18(38)$ & $16(89)$ & $20(43)$ & $20(100)$ \\
\hline Two (27) & $6(22)$ & $0(0)$ & $16(59)$ & $12(75)$ & 5(19) & $5(100)$ \\
\hline Three (85) & $17(20)$ & $6(35)$ & $50(59)$ & $33(66)$ & $18(21)$ & $18(100)$ \\
\hline Four (39) & $10(26)$ & $3(30)$ & $25(64)$ & 17(68) & $4(10)$ & $4(100)$ \\
\hline Five (30) & $16(53)$ & $4(25)$ & $11(37)$ & $4(36)$ & $3(10)$ & $2(66)$ \\
\hline
\end{tabular}


are willing to use HRT or bisphosphonates if indicated. It would also seem reasonable to offer a BMD scan to women who have already used HRT for 5 years and are weighing up the risks and benefits of continuing.

\section{Acknowledgements}

The authors would like to thank Dr Hannan and Carol Miller at Medical Physics, the Western General Hospital, Edinburgh, for their help in providing data. They would also like to thank Morag Kilgour for her unerring ability to track down patient notes.
Statements on funding and competing interests

Funding. None.

Competing interests. None.

References

Muir K, Kennie DC, Kerr TS, et al. Hip Fracture. Scottish Needs Assessment Programme 1997, Scottish Forum For Public Health Medicine, Glasgow.

Fogelman I. Screening for osteoporosis. BMJ 1999; 319: 1148-149.

ell mesures of bone minera density predict occurrence of osteoporotic fractures. BMJ 1996; 312: 1254-1259.

Gebbie AE, Caird L, Glasier A. A community menopause clinic in Edinburgh - five years experience. Br J Fam Plan 1996, 22: 46-49.

and Treatment of Osteoporosis. London: Department of Health, 1998.

Dempster DW, Lindsay R. Pathogenesis of osteoporosis Lancet 1993; 341: 797-805.

Eriksen EF, Kassem M. The clinical problem of treating. Lano rosis with estrogens. In: Studd J. (ed ) The Management of the Menopause. Annual Review 1998. Carnforth: Parthenon Publishing Group, 1998. 